\title{
AN INSECT PEST OF SASKATOONS
}

T. D. BETHUNE, D. M. LEHMKUHL and T. A. STEEVES, Department of Biology University of Saskatchewan, Saskatoon.

Most residents of Saskatchewan are familiar with the saskatoon, Amelanchier alnifolia Nutt. The range of this plant, however, encompasses a much larger area of North America (Fig. 1) making it the most widespread member of the genus Amelanchier. It is characteristically found in coulees, bluffs, creekbeds, or open woodlands throughout its range and is known by such local names as Juneberry, Serviceberry, Shadbush or Petites Poires. ${ }^{1}$ In this province the berries are well known for their sweet, distinctive flavour and excellent freezing and canning qualities which make them one of our most sought after natural crops. Cultivated varieties such as 'Smokey' or 'Pembina' are available but cultivation is not extensive and most people rely on natural crops, when available. ${ }^{2}$ The plant has excellent potential as a fruit crop for the prairie region and attempts are currently underway to develop it in this respect.

It is well known that although wild saskatoons can produce heavy crops of fruit, production tends to be very unreliable and heavy crop years in a given locality are often interspersed by several seasons in which little or no fruit of any quantity or quality can be found. A number of reasons including such factors as late spring frost, spring drought or high winds during blossoming are often put forth by local residents to explain this variability. No single explanation, however, appears to be conclusive and although any one of a combination of these factors may contribute to crop failures, observations we have carried out over a five-yea period at one location eliminated all o these climatic factors as the fun damental cause of crop failures Indeed, complete crop failures were recorded in seasons in which al weather conditions seemed to be entirely favourable for good berry production. This was most perplexing and a detailed investigation was undertaken to try and find a more plausible explanation for the variability observed in fruit production.

\section{The Survey}

To try and determine whether variations in crop production are a localized phenomenon or whether they extend over wide areas of the province, a survey was carried out in which selected members of Saskatchewan Natural History Society were contacted in the winter of 197677 and asked to rate the saskatoon crop in their area as good, fair or poor for the 1975 and 1976 crop years. The results of this survey showed that variability in saskatoon production indeed tends to be very localized and that it follows no pattern over broad areas. Wide fluctuations were noted in adjacent areas (Fig. 2), strongly suggesting that climatic factors are not the sole cause of the crop failures.

\section{Phenology}

Phenological studies of fruiting saskatoon branches were undertaken in the spring of 1976 and 1977. Individual branches at a rural site approximately 35 miles from Saskatoon (S.W. 31-31-6) on the 


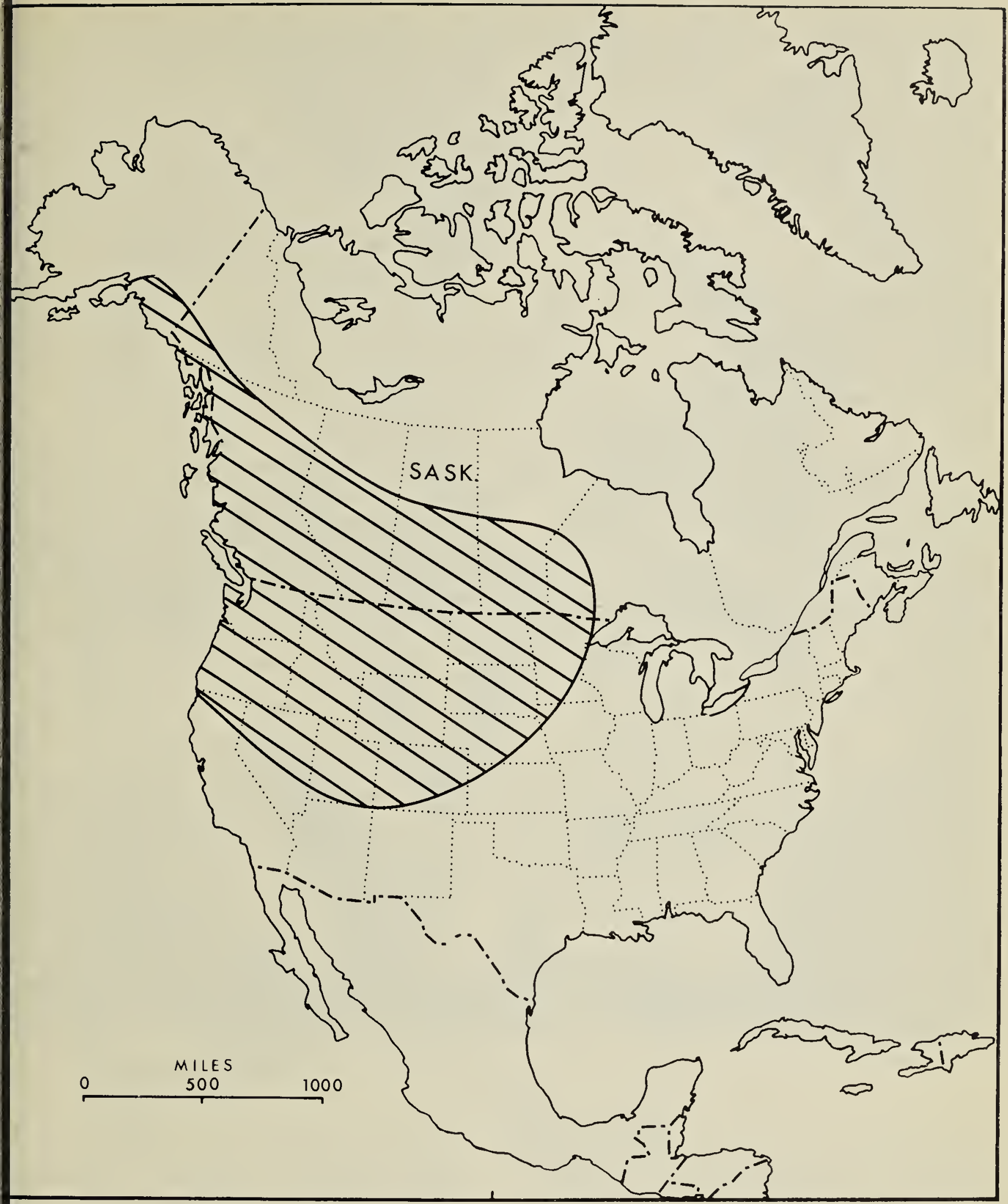

igure 1. Range of the saskatoon, Amelanchier alnifolia Nutt., in North America.

anks of the South Saskatchewan iver were tagged and the progress of erry development documented. hese data are summarized in Table It can be seen that fruit set express$d$ as a percentage of blossoms riginally present was high, in both ears, indicating that successful ollination had occurred. As the fruits were approaching their mature size, the counts were repeated and at this time, in all cases, a dramatic drop in fruit number had occurred. A further drop in number was recorded when the ripe fruits were harvested at the end of the season. When these harvested fruits were brought into the laboratory for detailed examination, it 


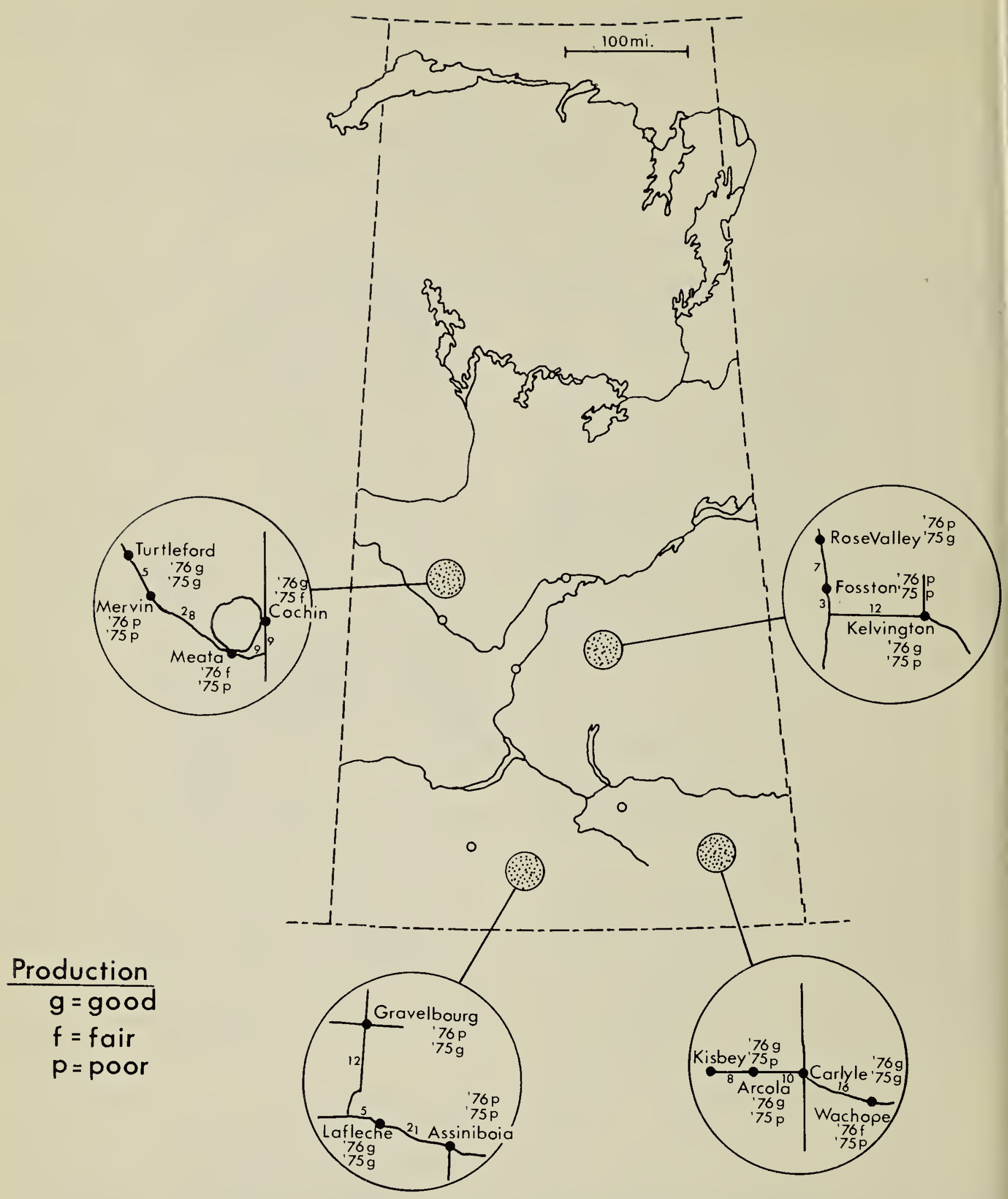

Figure 2. Four examples of saskatoon crop fluctuations in Saskatchewan, 1975 and 1976.

quickly became evident that an even lower percentage of the fruits could be considered at all desirable or useable. Most of the berries were heavily damaged, apparently by insects; the most common type of wound being a deep puncture (Fig. 3). Dissections of harvested fruits also revealed larvae and pupal stages in many berries indicating the active in- volvement of an insect in damage to developing fruits.

\section{The Insect}

The punctures noted on damaged berries were indicative of an insect of the weevil type. Collections were made on and about clumps of saskatoons and beetles of this type were found. Specimens collected 


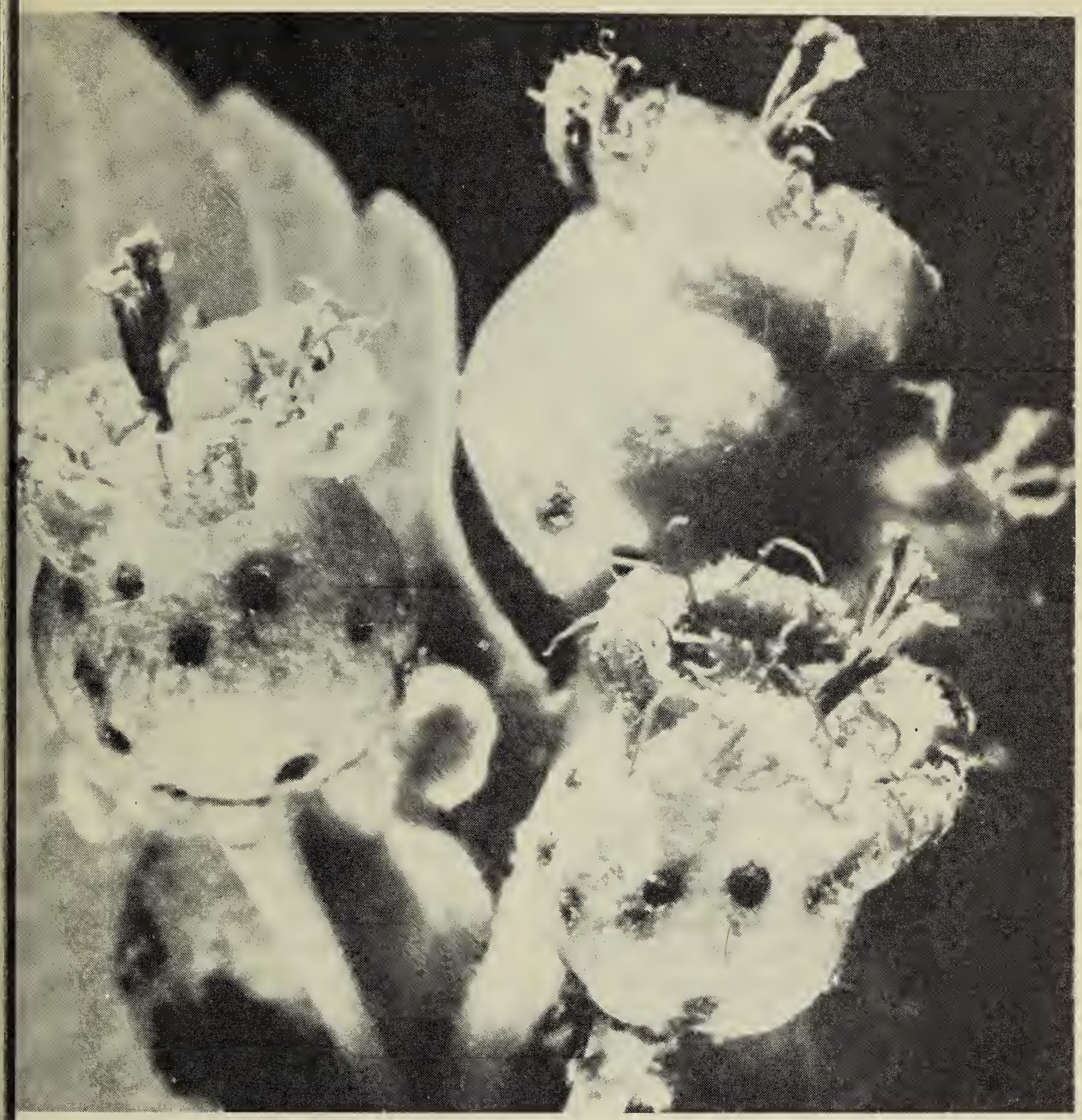

igure 3. Curculio punctures to saskatoon berries.

Vere sent to the Biosystematics Research Institute in Ottawa where hey were identified as Tachypterellus uadrigibbus Say, the apple curculio Fig. 4). This insect resembles the well nown rose curculio but is approxmately one-half the size. The species - widely distributed in North America nd has been described as a pest in rchards of apples, plums, cherries, eaches etc. References were found 0 its presence on Amelanchier but no dication of damage was provided. ${ }^{34}$

Since populations of the curculio at he rural site seemed small and in- adequate to account for the extensive puncture damage observed, curculios were brought into the laboratory for controlled feeding experiments. Single beetles were placed in vials, each with one freshly collected fruit and the fruit was scored for feeding punctures. An average of 11.1 punctures per berry over a $40 \mathrm{hr}$ period indicated that a single curculio is capable of inflicting severe injury and that a large and conspicuous population would not be necessary to account for the heavy damage observed to berries in the field. Moreover, since 


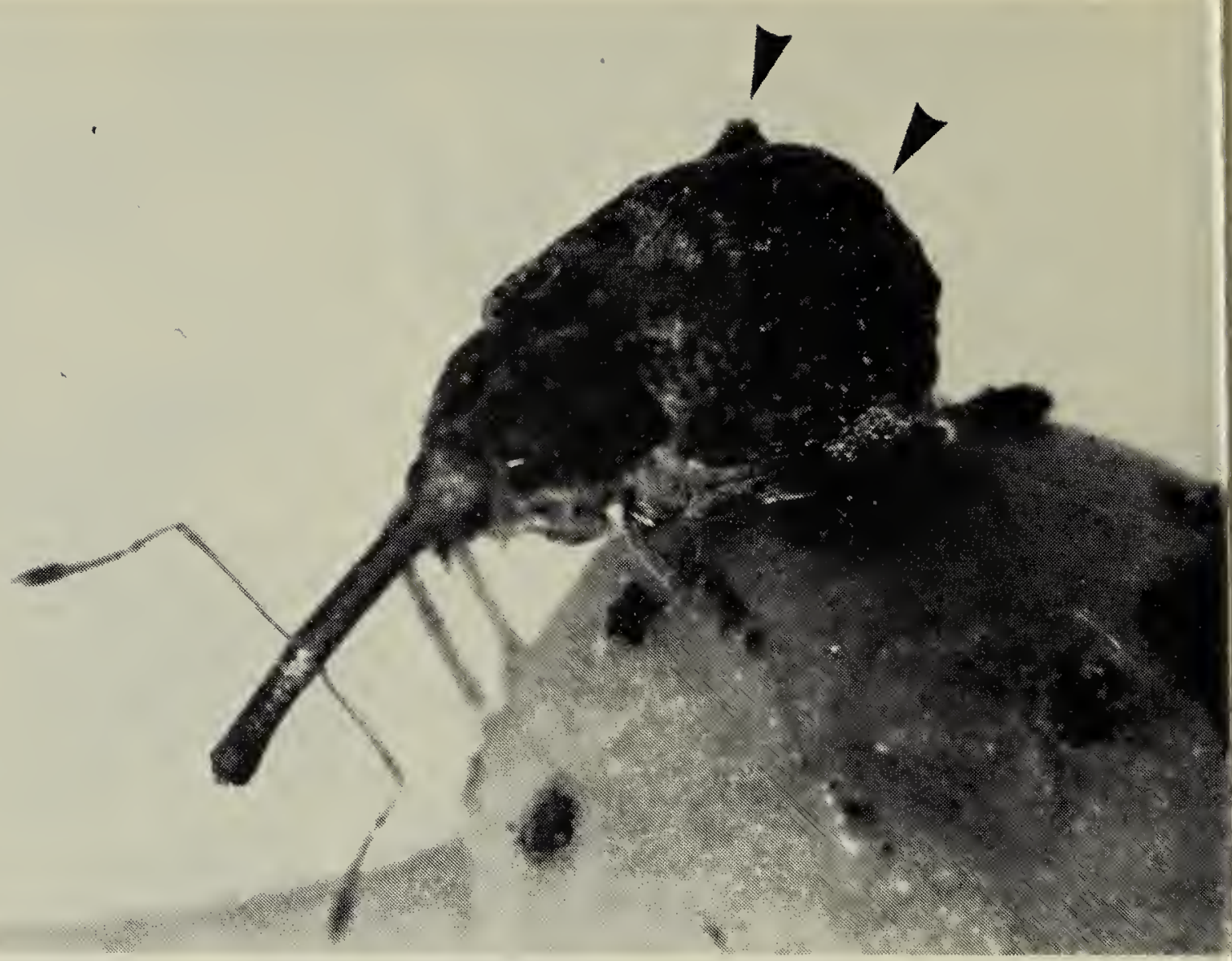

Figure 4. The apple curculio, Tachypterellus quadrigibbus Say, (note characteristic bumps on elytra.)

punctures observed in this experiment were identical to those found in nature, it is reasonable to conclude that the apple curculio collected on and around fruiting saskatoon bushes is responsible for the extensive damage observed to developing fruits, many of which drop as a result.

\section{Fruit Protection}

In 1976, six fruit-bearing branches were protected at the rural site on 24 May when the fruit was developing but already showed signs of curculio damage. The fully ripe fruit was harvested on 8 July. Many shrivelled, dropped fruits as well as retained damaged fruits were found, but the proportion of large, unpunctured berries $(18.6 \%)$ was still substantially higher than that found on unprotected branches $(0.3 \%)$. A similar experiment was carried out in 1977 when two branches were covered on each of four occasions: 13, 23, 28 May, and 3 June. For one of the two branches protected on each occasion a record of fruit set had been made ir mid-May, just after pollination. The fruits were harvested and examineo when fully ripe in early July. The results confirmed the findings of the previous season, but indicated a progressive decline in the proportion of unpunctured fruits with increased exposure prior to bagging. ${ }^{6}$ Since counts had been made of the original number of fruit set, it was also possible to determine the effects of protection on berry retention, as well as quality. It was found that bagging even as late as 3 June markedly reduced fruit drop $(59 \%$ retained as opposed to $39 \%$ on the controls) and that earlier protection resulted in retentions as high as $90 \%{ }^{6}$

In 1978 , our study was expanded to include an urban site on an acreage just south of the city. Fruit set was recorded on marked branches at both sites shortly after pollination. Some branches were left untouched as controls, while others were bagged on successive dates for five weeks at 
TABLE 1. Flowering and fruit set of the saskatoon, rural site, 1976 and 1977.

$\begin{array}{lcccccc}\text { Year } & \begin{array}{c}\text { No. } \\ \text { branches }\end{array} & \begin{array}{c}\text { No. } \\ \text { flowers }\end{array} & \begin{array}{c}\text { Immature* } \\ \text { fruit }\end{array} & \begin{array}{c}\text { Maturing** } \\ \text { fruit }\end{array} & \begin{array}{c}\text { Mature** } \\ \text { fruit }\end{array} & \begin{array}{c}\text { Desirable** } \\ \text { fruit }\end{array} \\ 1976 & 20 & 2437 & 2125(87.2) & 781(36.8) & 676(31.8) & 2(0.09) \\ 1977 & 9 & 1186 & 731(61.6) & 464(63.5) & 456(62.4) & 24(3.3)\end{array}$

* \%'s (in brackets) compared to the original flower number

**\%'s (in brackets) compared to the number of immature fruit set

both sites. All observations were terminated and fruit collected during the first week in July. Collected fruit was brought back to the laboratory for detailed examination.

Damage at the rural site was extremely severe, even early in the season when the original counts of immature fruit set were made. Despite the fact that branches were protected by bagging, little positive effect on berry retention was noted. The effect of bagging on berry quality, however, was more conclusive. The only perfect berries found in the field at the fural site were those on branches protected from the curculios. A brogressive decline in berry quality with increased exposure prior to bagging was evident.

Damage at the urban site was not pearly so severe, perhaps reflecting he variations observed in the berry rrop throughout the province. Trends poted in earlier phenological work were clearly evident at the urban site. Retentions were higher on branches bagged earlier than on those protected later and berry quality lecreased with increased exposure prior to bagging. The unprotected fontrol branch had only $16.2 \%$ unpunctured berries at harvest, compared to $63.0 \%$ on the branch bagged 24 May. This decline in berry quality with increased exposure to the curfulios is shown in Figure 5.

\section{Discussion}

Despite the overall popularity of the saskatoon, no serious investigations have ever been carried out to provide an explanation for the frequent and characteristic crop failures in this area. Considering the potential of the saskatoon as an economic crop for the prairie region, an explanation for these crop failures is essential.

It is clear from evidence presented in this report that the feeding and reproductive activity of the apple curculio has a pronounced effect on both retention and quality of fruit produced by saskatoons at the sites investigated. Although other factors cannot be entirely eliminated, we feel that the activity of this beetle is the major cause of the crop failures observed. Extensive feeding damage to blossoms and young berries causes them to drop and therefore substantially decreases retentions. Feeding damage later in the season when the berries are larger and more mature apparently does not cause actual fruit loss, but substantially reduces the quality of the fruit retained. Fruit quality is also affected by egg-laying and subsequent development of larval and pupal stages within the berries. It appears that those fruits in which eggs are laid remain attached until the adult emerges.

It is evident from the survey results 


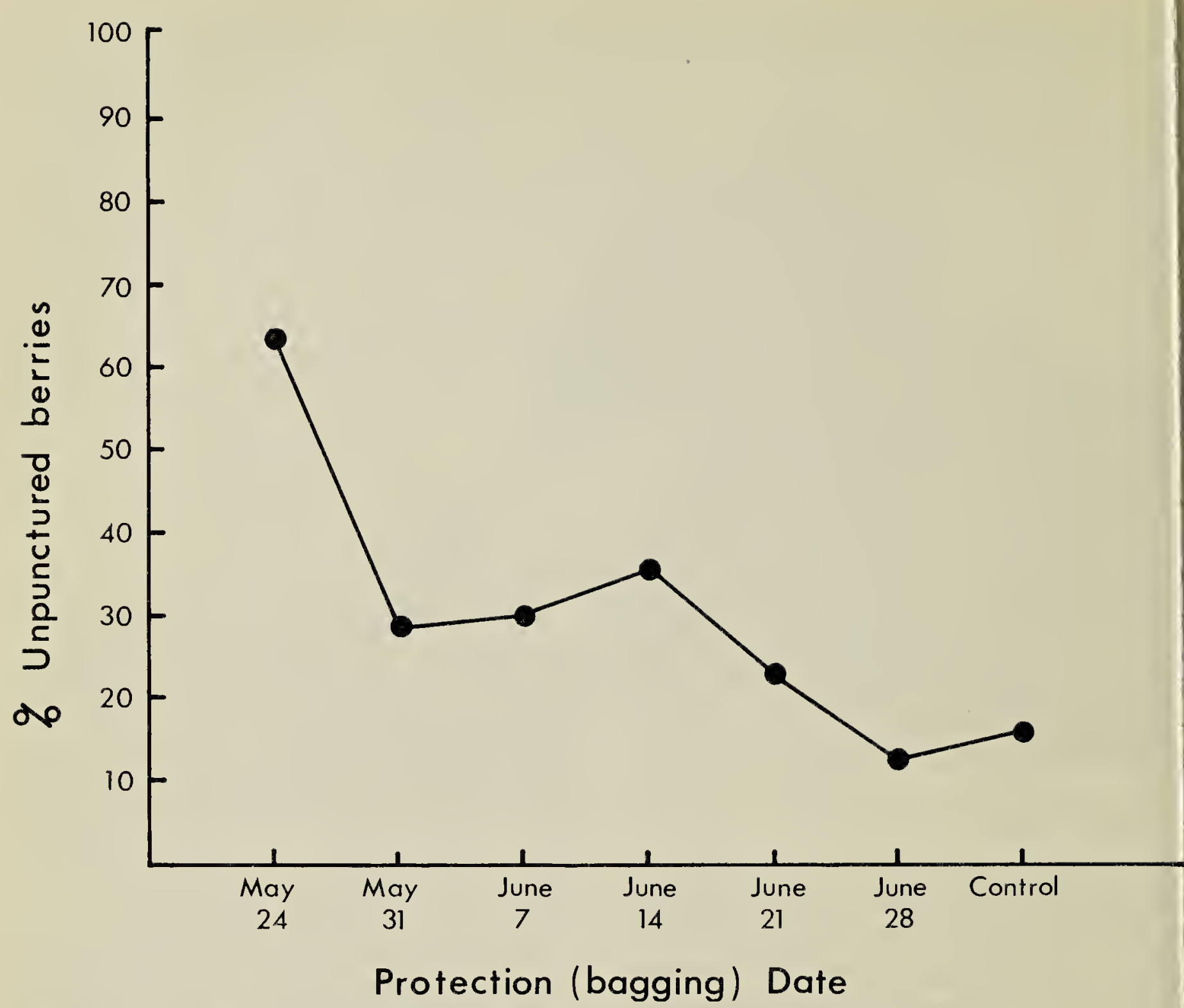

Figure 5. The effect of protection date on berry quality, urban site, 1978.

that there is a pronounced local variation in severity of damage to the fruit. Several factors can influence this. Of prime importance must be the population level of the curculio. In those areas in which a high population has developed, one would then expect a corresponding increase in extent and severity of damage. Extension of our present study to include several other localities in the province is necessary to expand upon this idea. Published reports indicate particular habits of the apple curculio that could also influence the local variations in crop production observed. ${ }^{35}$ Although capable of strong flight, the beetles do not migrate extensively in any one season. It would thus be expected that local conditions influencing either the population size or the activity of the apple curculio could result in substantial differences in the extent ano severity of damage inflicted.

Temperature also appears to play an important role. List has reportec that at temperatures below $55^{\circ} \mathrm{F}$ $\left(13^{\circ} \mathrm{C}\right)$ the activity of the insects is depressed. ${ }^{3} \mathrm{Cool}$, rainy weather in the early stages of berry development could result in decreased curculio activity and thus reduce the damage potential. It is difficult, however, to visualize this single weather condition as the sole source of the highly localized variations in crop development and insect activity and further work is required to determine what other factors may be involved.

It is often difficult to find curculios in natural stands of saskatoons unless extensive attempts at collection are 
made even though damage is evident rom close examination of the fruit. This may be related to their habit, when disturbed, of feigning death and dropping to the ground. Their colouration also helps to make them ndistinguishable since they blend in well with bud scales and twigs. These characteristics, coupled with the fact hat few people actually examine ruiting stands of the saskatoon until bicking time may account for the fact hat the beetle and its activities have gone unnoticed for so long. The fact does remain, however, that the apple curculio does indeed have an imbortant role to play in influencing etention and quality of fruit produced py the saskatoon. Further information o clarify some of the outstanding broblems remaining is necessary and $t$ is hoped that expansion of our present investigation will shed still more light on the matter. We would velcome any information concerning his problem and take this opportunity o express our gratitude to those who esponded to our initial survey. Reprints of our article to be published in the Canadian Entomologist or of this article will be available on request.

'FERNALD, M. L. 1950. Gray's Manual of Botany. 8th ed. American Book Company, New York.

${ }^{2}$ HARRIS, R. E. 1972. The Saskatoon. Publication 1246, Inf. Div. Canada Dept. of Agriculture, Ottawa. Revised 1972.

${ }^{3}$ LIST, G. J. 1932. A Cherry Pest in Colorado. Col. Agr. Exp. Sta. Bull. 385:106 pp.

${ }^{4}$ METCALF, C. L., W. P. FLINT and R. L. METCALF. 1962. Destructive and Useful Insects. 4th ed. McGraw-Hill Book Co., New York.

${ }^{5}$ RITCHER, P. O. 1936. Host Relationships of the larger apple curculio, Tachypterellus quadrigibbus magnus List. Jour. Kans. Ent. Soc. 9 (3):94-99.

${ }^{6}$ STEEVES, T. A., D. M. LEHMKUHL and T. D. BETHUNE. Damage to saskatoons, Amelanchier alnifolia Nutt., by the Apple Curculio, Tachypterellus quadrigibbus Say (Coleoptera: Curculionidae). The Canadian Entomologist (in press) 1979.

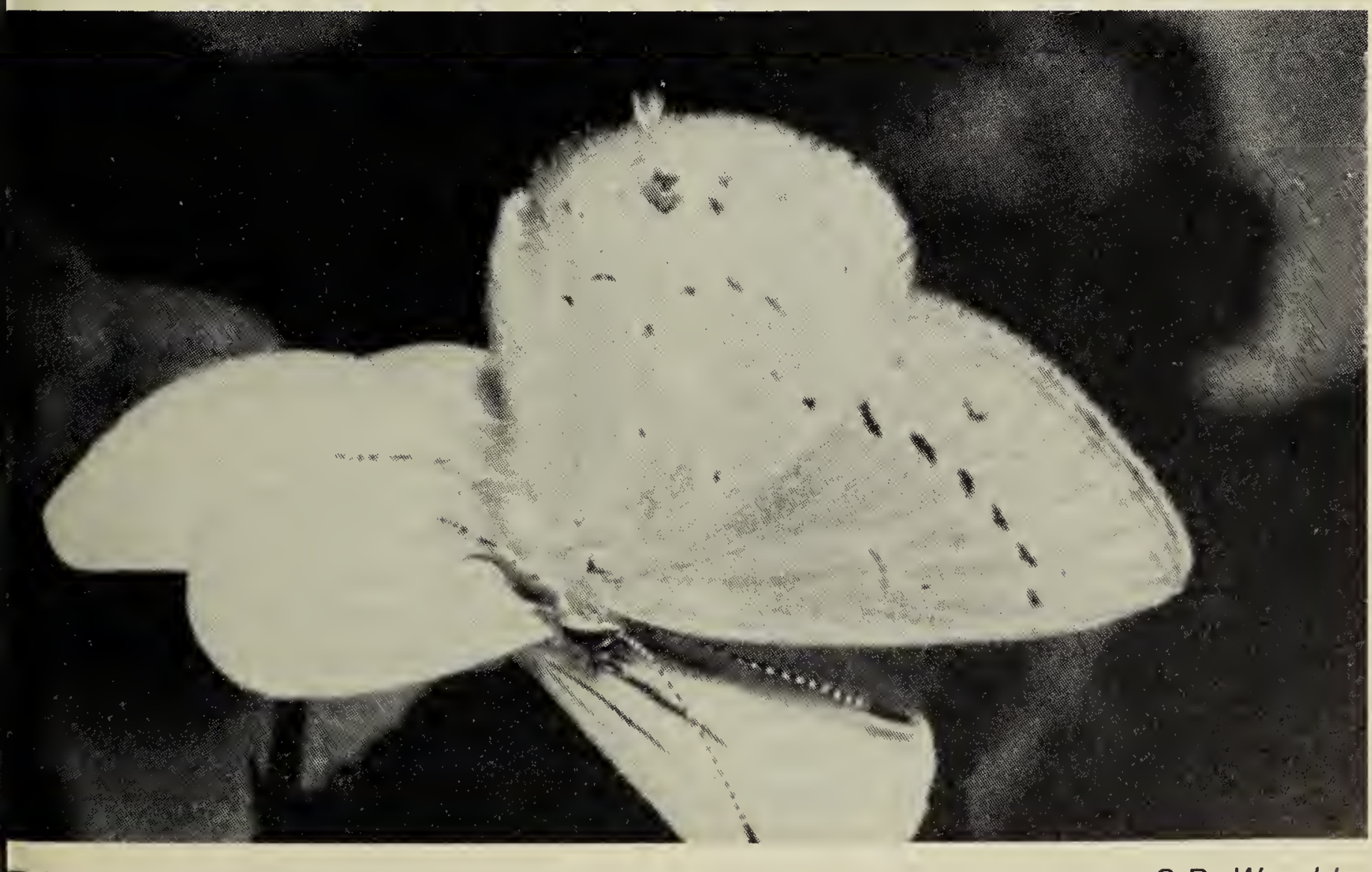

